\title{
A Nested Case-Control Study on Association Between Hepatitis C Virus Antibodies and Primary Liver Cancer in a Cohort of 9,775 Men in Taiwan
}

\author{
Chao-Chin Chang, Ming-Whei Yu, Chih-Feng Lu, Czau-Siung Yang, and Chien-Jen Chen \\ Institute of Public Health, National Taiwan University College of Public Health, Taipei (C. -C. C., M.-W. Y., C.-J. C.), \\ National Institute of Preventive Medicine, Department of Health, Executive Yuan, Taipei (C.-F. L.), Institute of \\ Microbiology, National Taiwan University College of Medicine, Taipei (C. -S. Y.), and Institute of Biomedical Sciences \\ Academia Sinica, Taipei (C.-J. C.), Taiwan
}

\begin{abstract}
Most studies on the association between antibodies against hepatitis $\mathrm{C}$ virus (anti-HCV) and primary liver cancer (PLC) were limited to caseseries, or cross-sectional case-control studies leaving a controversy on causal temporality. A nested case-control study on 38 newly-developed PLC patients and 152 matched controls selected from a cohort of 9,775 men in Taiwan recruited from September, 1984, to February, 1986, was carried out to examine the relation between $\mathrm{HCV}$ infection and PLC. Case-control pairs were matched on age ( \pm 1 year), residence, and the date at recruitment. Serum samples collected from study subjects at the initial recruitment were examined for anti-HCV by enzyme immunoassay and hepatitis $B$ surface antigen (HBsAg) by reverse passive hemagglutination assay combined with radioimmunoassay. History of cigarette smoking, alcohol consumption, vegetable consumption, vegetarian habit, and chronic liver diseases were also obtained through standardized interviews according to a structured questionnaire at the recruitment. After adjusting for $\mathrm{HBsAg}$ status and other risk factors, the anti-HCV was significantly associated with the development of PLC showing a multivariate-adjusted relative risk of 88.24 . The results suggest that $\mathrm{HCV}$ infection may play an important role in the etiology of human PLC in Taiwan.

(C) 1994 Wiley-Liss, Inc.
\end{abstract}

KEY WORDS: hepatitis C virus, primary liver cancer, cohort study

\section{INTRODUCTION}

In Taiwan, cirrhosis of the liver and primary liver cancer (PLC) are among the ten leading causes of death [Lin et al., 1986]. The role of hepatitis B virus (HBV) has been investigated extensively. Chronic HBV infection is undoubtedly the most important etiologic factor of hepatocellular carcinoma (HCC) in Taiwan [Beasley et al., 1988]. Recently, cigarette smoking, drinking alcohol, family history of HCC, aflatoxin, and serum testosterone level have also been identified as risk factors of HCC in Taiwan [Chen et al., 1991; Chen et al., 1992; $\mathrm{Yu}$ and Chen, 1993]. Hepatitis C virus (HCV) is associated with the development of HCC in Taiwan as in other countries [Chen et al., 1990; Jeng and Tsai, 1991; Yu et al., 1991; Chuang et al., 1992]. However, most previous studies aimed to explore the association between HCV and HCC were limited to case-series studies [Chen et al., 1990; Jeng and Tsai, 1991] or crosssectional case-control studies [Yu et al., 1991; Chuang et al., 1992]. These studies collected blood samples for anti-HCV tests after the diagnosis of HCC have left a controversy on causal temporality. There has never been a cohort study on the role of $\mathrm{HCV}$ in the development of HCC. A cohort of 9,775 men was recruited from September, 1984, to February, 1986, to study multiple risk factors of major cancers in Taiwan [Chen et al., 1993]. This nested case-control study on 38 newly-developed PLC cases and 152 matched healthy controls selected from this cohort was carried out using serum samples collected and frozen before the onset of PLC to investigate the role of $\mathrm{HCV}$ infection in the etiology of PLC.

\section{PATIENTS AND METHODS \\ Study Cohort Recruitment, Case Identification, and Control Selection}

The study cohort consisted of 9,775 men aged $30-85$ years who were invited to participate in a communitybased cancer screening project in Taiwan. They were initially recruited from six townships of Taiwan including Hsinpuu, Kuanhsi, Hengshan, Yuanshan, Chutien, and Checheng between September, 1984, and Febru-

Accepted for publication November 10, 1993.

Address reprints requests to Prof. Chien-Jen Chen, Institute of Public Health, National Taiwan University College of Public Health, Jen-Ai Road Section 1, Taipei 10018, Taiwan. 
ary, 1986. They were followed by telephone and homevisit interviews annually until March 1992 . The follow-up period ranged from 0.5 to 6.0 years. The vital status of study subjects was double-checked by data linkage with national death certification system using national identification number, sex, and birth date as matching variables. All death certificates were reviewed to examine the causes of death for those who died. Although the coding of liver cancer (ICD-9 code 155) in death certificates included cancers of the liver and the intrahepatic bile duct (ICD 155) according to the 8th Revision of the International Classification of Diseases, Injuries and Causes of Death, more than 95\% of deaths classified into this category in Taiwan were HCC. Because HCC is a common fatal cancer in Taiwan and most of $\mathrm{HCC}$ patients are referred to teaching hospitals for diagnosis and treatment, the possibility of misdiagnosis of HCC was considered as low. The most accepted diagnostic criteria for HCC in Taiwan are assigned on the basis of either pathological examinations or an elevated alpha-fetoprotein level $(\geqslant 400 \mathrm{ng} / \mathrm{ml})$ combined with at least one positive image on angiography, ultrasonography, and computerized tomography. During the follow-up period, 55 newly-diagnosed PLC cases were identified. The annual incidence of PLC was 117 per 100,000 persons. As the frozen serum samples were not available for 17 PLC patients to test for anti$\mathrm{HCV}$, the statistical analysis was based on the data of 38 matched case-control sets. The comparison of baseline data from the 38 cases that we studied with data from the other 17 eligible cases showed that the two groups were comparable with respect to all the demographic characteristics and distributions of potential HCC risk factors. It seems reasonable to assume that the patients used in this study are representative of the eligible cases. As only 38 PLC patients were included in this study and the anti-HCV prevalence in the general population in Taiwan was rather low, to obtain a more precise estimate of the relative risk associated with anti-HCV, a 1:4 ratio of cases to controls was used in this study. The controls were matched individually to the patients on age ( \pm 1 year), residence, and the date at recruitment. They were selected randomly from all subjects who were alive and free from PLC on the date of the diagnosis of the given PLC cases to whom they were matched whenever the cases occurred.

\section{Serum Collection and Serological Examinations}

At the initial recruitment examination, a total of 15 $\mathrm{ml}$ blood was collected from each study subject. Serum samples were separated on the same day as blood collection. Two aliquots were frozen in deep freezers and transported in dry ice to the laboratory at National Taiwan University, College of Medicine. The serum samples were kept at $-30^{\circ} \mathrm{C}$ until examinations. Serum samples of 38 liver cancer cases and 152 matched controls were tested for anti-HCV in November, 1992. Anti-HCV was determined by a second-generation enzyme immunoassay (Abbott Laboratories. North Chicago, IL, U.S.A.) which is based on recombinant HCV peptides c-100-3 and c-33, as well as a recombinant structural peptide c-22 (putative core protein). Each sample was tested in duplicate. Only repeatedly positive samples were considered as anti-HCV positive. HBV surface antigen (HBsAg) was examined by reverse passive hemagglutination assay (RPHA) using commercial kits at the initial recruitment examination, and HBsAg-negative serum samples of both cases and controls were rechecked by radioimmunoassay (RIA) using commercial kits (Abbott Laboratories, North Chicago, IL) in April, 1993. Two cases and one control who were HBsAg-negative on RPHA at the recruitment examination were found to be HBsAg-positive on RIA. All laboratory examinations were performed blindly.

\section{Structured Questionnaire and Standardized Interview}

Each study subject was also interviewed personally according to a structured questionnaire on sociodemographic characteristics, long-term habits of cigarette smoking, alcohol drinking, and dietary pattern, as well as personal and family history of chronic liver diseases by well-trained public health nurses in local health centers. Habit of cigarette smoking was defined as having smoked cigarettes more than 4 days a week for at least 6 months. Alcohol drinking was defined as consumption of alcohol more than 3 days a week for at least 6 months. Vegetable consumption frequency was inquired as the number of meals consuming fresh vegetables per week. Vegetarian habit was defined as having one or more meals without food from animal sources every day for more than one year. Most vegetarians in Taiwan consume large amounts of pickled vegetables and fermented foods produced from peanuts or beans instead of fresh vegetables. The history of chronic liver diseases diagnosed by physicians for study subjects themselves and their first-degree relatives was also obtained.

\section{Statistical Methods}

Matched relative risks with their 95\% CI were estimated for various risk factors. In the multivariate analysis using conditional logistic models, only risk factors which were significantly associated with PLC $(P<0.10)$ were included in the regression equation.

\section{RESULTS Anti-HCV and HBsAg}

The anti-HCV seropositivity and HBsAg carriage among PLC patients and matched controls are shown in Table I. Anti-HCV was detected in 5 of $38(13.2 \%)$ PLC patients and only 4 of $152(2.6 \%)$ matched healthy controls. The association between anti-HCV status and PLC was statistically significant with a matched relative risk of 7.90 (95\% confidence interval $=1.49-41.79$, $P=0.015$ ). The HBsAg carrier rat was significantly higher among PLC patients than community controls $(63.2 \%$ versus $6.6 \%, P<0.05)$. Compared with $\mathrm{HBsAg}$ negative subjects as the referent, the matched relative 
TABLE I. Seropositivity of Anti-HCV and HBsAg in 38 PLC Cases and 152 Matched Controls From a Cohort of 9,775 Men in Taiwan

\begin{tabular}{|c|c|c|c|c|c|c|}
\hline \multirow[b]{2}{*}{ Variable } & \multicolumn{2}{|c|}{ Cases } & \multicolumn{2}{|c|}{ Controls } & \multirow{2}{*}{$\begin{array}{c}\text { Matched } \\
\text { relative risk } \\
(95 \% \text { C.I. })^{\mathrm{a}}\end{array}$} & \multirow[b]{2}{*}{$P$} \\
\hline & No. & $\%$ & No. & $\%$ & & \\
\hline \multicolumn{7}{|l|}{ Anti-HCV } \\
\hline Negative & 33 & 86.8 & 148 & 97.4 & 1.00 & \\
\hline Positive & 5 & 13.2 & 4 & 2.6 & $\begin{array}{l}7.90 \\
(1.49-41.79)\end{array}$ & 0.015 \\
\hline \multicolumn{7}{|l|}{ HBsAg } \\
\hline Negative & 14 & 36.8 & 142 & 93.4 & 1.00 & \\
\hline Positive & 24 & 63.2 & 10 & 6.6 & $\begin{array}{l}26.48 \\
(7.92-88.56)\end{array}$ & $<0.001$ \\
\hline \multicolumn{7}{|l|}{ Anti-HCV/HBsAg } \\
\hline Negative/negative & 10 & 26.2 & 138 & 90.8 & 1.00 & \\
\hline Positive/negative & 4 & 10.5 & 4 & 2.6 & $\begin{array}{l}34.04 \\
(3.54-327.80)\end{array}$ & 0.002 \\
\hline Negative/positive & 23 & 60.5 & 10 & 6.6 & $\begin{array}{l}44.57 \\
(10.17-195.30)\end{array}$ & $<0.001$ \\
\hline Positive/positive & 1 & 2.6 & 0 & 0.0 & $\infty$ & - \\
\hline
\end{tabular}

${ }^{\mathrm{a}} \mathrm{C} . \mathrm{I} .=$ confidence interval.

TABLE II. Cigarette Smoking, Alcohol Intake, Vegetable Consumption Frequency, Vegetarian Habit, and Chronic Liver Disease History of 38 PLC Cases and 152 Matched Controls From a Cohort of 9,775 Men in Taiwan

\begin{tabular}{|c|c|c|c|c|c|c|}
\hline \multirow{2}{*}{$\begin{array}{l}\text { Variable } \\
P\end{array}$} & \multicolumn{2}{|c|}{ Cases } & \multicolumn{2}{|c|}{ Controls } & \multirow{2}{*}{$\begin{array}{l}\text { Matched } \\
\text { relative risk } \\
(95 \% \text { C.I. })^{\mathrm{a}}\end{array}$} & \multirow[b]{2}{*}{$P$} \\
\hline & No. & $\%$ & No. & $\%$ & & \\
\hline \multicolumn{7}{|c|}{ Cigarette smoking } \\
\hline No & 11 & 28.9 & 50 & 32.9 & 1.00 & \\
\hline Yes & 27 & 71.1 & 101 & 66.4 & $\begin{array}{l}1.22 \\
(0.55-2.71)\end{array}$ & 0.620 \\
\hline \multicolumn{7}{|c|}{ Alcohol intake (ml/day) } \\
\hline$\leqslant 50$ & 32 & 84.2 & 133 & 93.7 & 1.00 & \\
\hline$>50$ & 2 & 5.3 & 9 & 6.3 & $\begin{array}{l}0.94 \\
(0.19-4.59)\end{array}$ & 0.937 \\
\hline \multicolumn{7}{|c|}{ Vegetable consumption (meals/week) } \\
\hline$\geqslant 6$ & 29 & 76.3 & 133 & 87.5 & 1.00 & \\
\hline$<6$ & 8 & 21.1 & 17 & 11.2 & $\begin{array}{l}3.26 \\
(0.96-11.01)\end{array}$ & 0.058 \\
\hline \multicolumn{7}{|c|}{ Vegetarian habit } \\
\hline No & 33 & 86.8 & 140 & 92.1 & 1.00 & \\
\hline Yes & 5 & 13.2 & 10 & 6.6 & $\begin{array}{l}2.53 \\
(0.69-9.24)\end{array}$ & 0.160 \\
\hline \multicolumn{7}{|c|}{ Chronic liver disease history } \\
\hline No & 32 & 84.2 & 147 & 96.7 & 1.00 & \\
\hline Yes & 6 & 15.8 & 5 & 3.3 & $\begin{array}{l}5.51 \\
(1.54-19.72)\end{array}$ & 0.009 \\
\hline
\end{tabular}

${ }^{2} \mathrm{C} . \mathrm{I} .=$ confidence interval.

risk of developing PLC was 26.48 (95\% confidence interval $=7.92-88.56, P<0.001)$ for $\mathrm{HBsAg}$ carriers. Anti-HCV was detected in 28.6\% (4/14) of HBsAg-negative PLC patients, $4.2 \%$ (1/24) of HBsAg-positive PLC patients, $2.8 \%$ (4/142) of HBsAg-negative matched controls, and $0 \%(0 / 10)$ of $\mathrm{HBsAg}$-positive controls. Compared with those who were negative on both anti-HCV and $\mathrm{HBsAg}$ as the referent, the relative risk of developing PLC was 34.04 (95\% confidence interval $=3.54-$ 327.80) for those who were HBsAg-negative and antiHCV-positive, and 44.57 (95\% confidence interval $=10.17-195.30$ ) for those who were HBsAg-positive and anti-HCV-negative. Because no controls were posi- tive for both $\mathrm{HBsAg}$ and anti-HCV, there was no finite estimate of relative risk for co-positivity of $\mathrm{HBsAg}$ and anti-HCV.

Cigarette Smoking, Alcohol Consumption, Vegetable Consumption, Vegetarian Habit, and Past Liver Disease History

Table II compares the cigarette smoking, alcohol intake, vegetable consumption frequency, vegetarian habit, and personal chronic liver disease history between PLC cases and matched community controls. No statistically significant associations with PLC were observed for cigarette smoking, alcohol intake, and vege- 
TABLE III. Conditional Logistic Regression Analysis of Multiple Risk Factors Associated With PLC

\begin{tabular}{|c|c|c|c|}
\hline Variable & Comparison & $\begin{array}{c}\text { Multivariate-adjusted } \\
\text { relative risk } \\
(95 \% \text { C.I. })^{\mathrm{a}}\end{array}$ & $P$ \\
\hline $\mathrm{HBsAg}$ & Positive versus negative & $\begin{array}{l}81.82 \\
(9.04-740.70)\end{array}$ & $<0.001$ \\
\hline Anti-HCV & Positive versus negative & $\begin{array}{l}88.24 \\
(5.16-1509.00)\end{array}$ & 0.002 \\
\hline $\begin{array}{l}\text { Vegetable consumption } \\
\text { (meals/week) }\end{array}$ & $<6$ versus $>6$ & $\begin{array}{l}17.77 \\
(0.97-325.70)\end{array}$ & 0.052 \\
\hline $\begin{array}{l}\text { Chronic liver disease } \\
\text { history }\end{array}$ & Yes versus no & $\begin{array}{l}16.41 \\
(1.01-267.60)\end{array}$ & 0.050 \\
\hline
\end{tabular}

${ }^{\mathrm{a} C . I .}=$ confidence interval.

tarian habit in this study. There was a significant association between vegetable consumption frequency and PLC with a relative risk of 3.26 (95\% confidence inter$\mathrm{val}=0.96-11.01, P=0.058$ ) for those who consumed vegetable less than six meals per week as compared with those who had weekly consumption frequency of six or more meals. Personal history of chronic liver diseases was also significantly associated with PLC. The relative risk of developing PLC for those who had a history of physician-diagnosis was 5.51 (95\% confidence interval $=1.54-19.72, P=0.009)$ as compared with those who never had the history.

\section{Multivariate Analysis}

Results of the conditional logistic regression analysis of multiple risk factors associated with PLC are shown in Table III. In the univariate analyses, anti-HCV seropositivity, HBsAg carrier status, vegetable consumption frequency, and history of chronic liver disease were significantly associated with PLC and thus included in the multivariate analysis. The multivariate-adjusted relative risk was 88.24 for those who were positive for anti-HCV as compared with those who were negative $(P=0.002)$. The multivariate-adjusted relative risk was as high as 81.82 for $\mathrm{HBsAg}$ carrier status $(P<0.001)$. History of chronic liver diseases was also associated significantly with the development of PLC showing a multivariate-adjusted relative risk of 16.14 $(P=0.05)$. As compared with those who consumed vegetables six or more meals per week, those who had the vegetable consumption frequency of less than six meals per week had a higher risk of developing HCC with a multivariate-adjusted relative risk of 17.77 $(P=0.052)$.

\section{DISCUSSION}

Although HBsAg carriage is associated with HCC, the disease does not develop in all HBsAg carriers. Other viral or environmental cofactors may also contribute to the development of HCC. Recent studies suggested that $\mathrm{HCV}$ may be an independent determinant of HCC [Jeng and Tsai, 1991; Chen et al., 1993; Lee et al., 1992]. The foregoing studies were all limited to cross-sectional designs in which serological marker of HCV infection was determined at the time or after the diagnosis of HCC. It is therefore difficult to justify a correct temporal relationship between $\mathrm{HCV}$ infection and HCC. There has never been a cohort study to solve the ambiguity, the causation between HCV and HCC remains unclear. This nested case-control study was derived from a cohort of 9,775 men who had been followed for 0.5-6.0 years. The serum samples of cases were collected before the diagnosis of PLC and controls were matched with cases on recruitment date. A significant association with PLC was observed for anti-HCV status before the PLC occurred.

The relative risk of developing PLC was as high as 7.90 for those who were positive on anti-HCV compared with those who were negative. The relative risk was greater than that estimated in our previous cross-sectional case-control study [Yu et al., 1991]. The serum samples of cases and matched controls were collected and frozen during the same time period in this study. Although it has been suggested that the storage of frozen samples may cause some false positive results for anti-HCV [Wong et al., 1990; Zavitsanos et al., 1992], the false positives may occur in serum samples of both cases and controls non-differentially. It is therefore reasonable to consider that using stored serum samples to test for anti-HCV in this study may not significantly bias the estimate of the relative risk associated with anti-HCV positivity. The population attributable PLC risk percentage was $15.2 \%$ for anti-HCV positivity and $63.6 \%$ for HBsAg carrier status. This was due mostly to a much higher prevalence for $\mathrm{HBsAg}$ carrier status than for anti-HCV seropositivity in the general population.

Primary liver cancer is multifactorial in origin. Both low vegetable consumption frequency and chronic liver disease history was associated significantly with PLC in the univariate analysis. These two factors were included in the conditional logistic regression model to adjust for their effect, the adjusted relative risk for anti-HCV was still statistically significant. Alcohol intake and cigarette smoking have been well documented as HCC risk factors [Chen et al., 1991; Lam et al., 1982; Hirayama et al., 1989]. The relative risk of anti-HCV remained significant after further adjustment for alcohol intake and cigarette smoking.

It was reported that anti-HCV positivity may not 
reflect the existence of virus in patients [Johnson et al., 1990], and HCV infection might not be an important risk factor of PLC. However, it has been shown that anti-HCV positivity is associated with the presence of HCV-RNA in serum by PCR indicating an ongoing virus replication [Miyamura and Saito, 1990].

The decreasing incidence of HBV-related HCC in Italy and Japan has been attributed to the increasing importance of HCV in the etiology of HCC. The development of HCC among patients affected with non-A, non-B post-transfusional hepatitis also indicate the role of HCV in the determination of HCC [Simonetti et al., 1991; Okuda, 1986; Stevens et al., 1990; Resnick et al., 1983; Gilliam et al., 1984; Kiyosawa et al., 1987; Wejstal et al., 1987; Tremolada et al., 1990]. In Japan, it was reported that $69 \%$ of 156 patients with $\mathrm{HCC}$ who were not infected by HBV were positive for anti-HCV compared with a seropositive rate of $4-10 \%$ in control groups [Saito et al., 1990]. However, the mechanism of HCV-associated hepatocarcinogenicity is still unclear. $\mathrm{HCV}$ is the single strain RNA virus without known oncogenes in its genome. HCV does not replicate via DNA intermediates to insert the viral gene into the cellular genomic DNA like HBV. Choo et al. [1990] considered that HCV may be involved only in the later stages of HCC carcinogenesis through its potential to cause chronic liver disease. In Taiwan, anti-HCV was present in $28(65 \%)$ of $43 \mathrm{HBsAg}$-negative patients with chronic hepatitis and $13(43 \%)$ of $30 \mathrm{HBsAg}$-negative cirrhosis [Chen et al., 1990]. These data indicated that HCV play a meaningful role in the chronic liver diseases including cirrhosis. Whether HCV may cause HCC independently through liver cirrhosis or by interaction with other cofactors deserves further investigation.

\section{ACKNOWLEDGMENTS}

This study was supported by a grant from the Department of Health, Executive Yuan, Republic of China.

\section{REFERENCES}

Beasley RP (1988): Hepatitis B virus: The major etiology of hepatocellular carcinoma. Cancer 61:1942-1956.

Chen DS, Kuo GC, Sung JL, Sheu JC, Chen PJ, Yang PM, Hsu HM, Chang MH, Chen CJ, Hahn LC, Choo QL, Wang TH, Houghton M (1990): Hepatitis C virus infection in an area hyperendemic for hepatitis B and chronic liver disease. The Taiwan experience. Journal of Infectious Disease 162:817-822.

Chen CJ, Liang KY, Chang AS, Chang YC, Lu SN, Liaw YF, Chang WY, Sheen MC, Lin TM (1991): Effects of hepatitis B virus, alcohol drinking, cigarette smoking and familial tendency on hepatocellular carcinoma. Hepatology 13:398-406.

Chen CJ, Zhang YJ, Lu SN (1992): Aflatoxin $B_{1}$ DNA adducts in smeared tumor tissue from patients with hepatocellular carcinoma. Hepatology 16:1150-1155.

Chen CJ, Yu MW, Wang CJ, Huang HY, Lin WC (1993): Multiple risk factors of hepatocellular carcinoma: a cohort study of 13737 male adults in Taiwan. 8:s83-87.

Choo QL, Weiner AJ, Overby LR, Kuo G, Houghton M, Dradley DW (1990): Prevalence of antibodies to hepatitis C virus in Italian patients with hepatocellular carcinoma. British Medical Bulletin 46:423-441.

Chuang WL, Chang WY, Lu SN, Su WP, Lin ZY, Chen SC, Heish MY, Wang LY, You SA, Chen CJ (1992): The role of hepatitis B and C viruses in hepatocellular carcinoma in a hepatitis $\mathrm{B}$ endemic area. Cancer 69:2052-2054.

El-Hassan AM, Ghalib HW, Zylstra E, Eltoum IA, Ali MS, Wong DC, Diwan AR, Rosen L, Gerin JL, Johnson RG, Polito A, Purcell RH (1990): Non-specificity of anti-HCV test for seroepidemiological analysis. Lancet 336:750-751.

Farber E (1991); Hepatocyte proliferation in stepwise development of experimental liver cell cancer. Digestive Diseases and Sciences 36:973-978.

Gilliam JH, Geisinger KR, Richter JE (1984): Primary hepatocellular carcinoma after chronic non-A, non-B hepatitis. Annals of Internal Medicine 101:794-795.

Hirayama TA (1989): Large-scale cohort study on risk factors for primary liver cancer, with special reference to the role of cigarette smoking (Suppl). Cancer Chemotherapy and Pharmacology 23: s114-117.

Jeng JE, Tsai JF (1991): Hepatitis C virus antibody in hepatocellular carcinoma in Taiwan. Journal of Medical Virology 34:74-77.

Johnson PJ, Zamon SN, King R, Williams R (1990): Antibodies to the hepatitis $\mathrm{C}$ virus (HCV) in hepatocellular carcinoma (HCC): relation to etiology of cirrhosis and immunoglobulin G levels (Suppl 2). Journal of Hepatology 11:553.

Kiyosawa K, Akahane Y, Nagata A, Furuta S (1987): Hepatocellular carcinoma after non-A, non-B post-transfusion hepatitis. American Journal of Gastroenterology 78:777-781.

Lam KC, Yu MC, Leung JWC, Henderson BE (1982): Hepatitis B virus and cigarette smoking: risk factors for hepatocellular carcinoma in Hong Kong. Cancer Research 42:5246-5248.

Lee SD, Lee FY, Wu JC, Hwang SJ, Wang SS, Lo KJ (1992): The prevalence of anti-hepatitis $\mathrm{C}$ virus among Chinese patients with hepatocellular carcinoma. Cancer 69:342-345.

Lin TM, Tsu WT, Chen CJ (1986): Mortality of hepatoma and cirrhosis of liver in Taiwan. British Journal of Cancer 54:969-970.

Miyamura T, Saito I (1990): Relation of hepatitis C virus infection to hepatocellular carcinoma. Presented at Second International Symposium on HCV, Los Angeles, November 1990.

Okuda K (1986): Primary liver cancer (Suppl.). Digestive Diseases and Sciences 31:133-145.

Resnick RH, Stone K, Antonioli D (1983): Primary hepatocellular carcinoma following chronic non-A, non-B post-transfusion hepatitis. Digestive Diseases and Sciences 28:908-911.

Saito I, Miyamura T, Ohbayashi A, Harada H, Katayama T, Kikuchi S, Watanabe Y, Koi S, Onji M, Ohta Y, Choo QL, Houghton M, Kuo $G$ (1990): Hepatitis C virus infection is associated with the development of hepatocellular carcinoma. Proceedings of the National Academy of Sciences of the U.S.A. 87:6547-6549.

Simonetti RG, Camma C, Fiorello F, Politi F, D'Amico G, Pagliaro L (1991): Hepatocellular carcinoma: a worldwide problem: the major risk factors. Digestive Diseases and Sciences 36:962-972.

Stevens CE, Taylor PE, Pindyck J, Choo QL, Bragley DW, Kuo G, Houghton M (1990): Epidemiology of hepatitis C virus. A prelimenary study in volunteer blood donors. Journal of the American Medical Association 263:49-53.

Tremolada F, Benvegnu L, Casarin C, Pontisso P, Tagger A, Alberti A (1990): Antibodies to hepatitis $C$ virus in hepatocellular carcinoma. Lancet 335:300-301.

Wejstal R, Lindberg J, Lundin P, Norkrans G (1987): Chronic non-A, non-B hepatitis. A long term follow-up study in 49 patients. Scandinavian Journal of Gastroenterology 22:1115-1122

Yu MW, Chen CJ (1993): Elevated serum testosterone levels and risk of hepatocellular carcinoma. Cancer Research 53:1-5.

Yu MW, You SL, Chang AS, Lu SN, Liaw YF (1991): Association between hepatitis $\mathrm{C}$ virus antibodies and hepatocellular carcinoma. Cancer Research 51:5621-5625.

Zavitsanos X, Hatzakis A, Kaklamani E, Tzonou A, Toupadaki N (1992): Association between hepatitis C virus and hepatocellular carcinoma using assays based on structural and nonstructural hepatitis C virus peptides. Cancer Research 52:5364-5367. 